\title{
PENGARUH EFIKASI DIRI DAN PERSEPSI IKLIM ORGANISASI TERHADAP KINERJA DENGAN EMPLOYEE ENGAGEMENT SEBAGAI VARIABEL MEDIATOR PADA KARYAWAN BMT BIF YOGYAKARTA
}

\author{
Nailul Fajriah, Marcham Darokah \\ Golden Consultan, Jl. Alamsyah RPN Gg. Julius 132 Kotabumi, Lampung Utara \\ nailulfajriah.inel@yahoo.co.id
}

\begin{abstract}
The purpose of this study is to examine what are the most affect factors to BMT BIF employee performance, in terms of self-efficacy and perceptions of organizational climate, moderated by employee engagement. This study uses a quantitative approach in an effort to test the hypotheses. The subjects were all employees of microfinance bank (BMT) BIF Yogyakarta totaling 93 people. Methods of data collection using a Likert scale with five answer options. Data were analyzed using Structural Equation Modeling (SEM) was run by AMOS 22.0 software. The results showed $19.4 \%$ of BMT BIF employee's performance is influenced by self-efficacy, the parameter coefficient of 0.440 and $P$ value $<0.05$. Selfefficacy significantly affect to employee performance of which is mediated by employee engagement. These results demonstrate the effective contribution of $17.6 \%$ with a coefficient parameter of 0.420 and $\mathrm{P}$ value $<0.05$. Perceive of organizational climate does not affect to BMT BIF employee performance, either directly or mediated by employee engagement.
\end{abstract}

Keywords: employee engagement, job performance. Perceived of organizational climate, self-efficacy

\begin{abstract}
Abstrak
Tujuan dari penelitian ini yaitu untuk menguji faktor apa yang paling mempengaruhi kinerja karyawan BMT BIF, ditinjau dari efikasi diri dan persepsi iklim organisasi dengan dimediasi oleh employee engagement. Penelitian ini menggunakan pendekatan kuantitatif dalam usaha menguji hipotesis yang telah disusun. Subjek penelitian adalah seluruh karyawan BMT BIF Yogyakarta yang berjumlah 93 orang. Metode pengumpulan data menggunakan skala Likert dengan lima pilihan jawaban. Teknik analisis data menggunakan Structural Equation Modeling (SEM) yang dijalankan dengan perangkat lunak AMOS 22.0. Hasil penelitian ini menunjukkan 19,4\% kinerja karyawan BMT BIF dipengaruhi oleh efikasi diri, dengan koefisien parameter sebesar 0,440 dan P value $<0,05$. Efikasi diri berpengaruh secara signifikan terhadap kinerja yang dimediasi oleh employee engagement. Hasil tersebut menunjukkan sumbangan efektif sebesar 17,6\% dengan koefisien parameter sebesar 0,420 dan $\mathrm{P}$ value $<0,05$. Adapun persepsi iklim organisasi tidak berpengaruh terhadap kinerja karyawan BMT BIF, baik secara langsung ataupun dimediasi oleh employee engagement.
\end{abstract}

Kata Kunci: efikasi diri, employee engagement, iklim organisasi, kinerja 


\section{Pendahuluan}

Perkembangan teknologi yang pesat berdampak pada perubahan yang terjadi di organisasi. Untuk dapat menyesuaikan diri dengan perkembangan teknologi dan bertahan dalam persaingan organisasi memerlukungan dukungan sumber daya yang memdai. Salah satu sumber daya yang memegang peran penting dalam perkembangan organisasi adalah sumber daya manusia. Sumber daya manusia akan mengolah sumber daya lain dengan memanfaatkan teknologi untuk mencapai tujuan organisasi.

Salah satu aspek penting dalam sumber daya manusia adalah kinerja. Menurut Bernardin (2003) kinerja merupakan catatan hasil atau outcome yang diproduksi oleh fungsi jabatan tertentu atau kegiatan yang dilakukan dalam periode waktu tertentu. kinerja diartikan sebagai prestasi kerja, yaitu perbandingan antara hasil kerja dengan standar yang ditetapkan (Dessler ,2000). Karyawan yang memiliki kinerja yang baik akan berdampak pada pencapaian tujuan organisasi.

Menurut Bonner dan Sprinkle (2002) kinerja karyawa dipengaruhi banyak faktor, baik faktor internal maupun ekstrenal. Faktor internal antara pengetahuan, kemampuan dan efikasi diri. kinerja dipengaruhi oleh faktor lingkungan atau iklim organisasi. Menurut Timpe (1992) perilaku manajemen karena perilaku manajemen yang baik atau sesuai harapan individu akan berdampak pada employee engagement.

Employee engagement didefinisikan sebagai keterikatan dan antusiasme karyawan terhadap pekerjaannya. Gallup menyamakan employee engagement dengan keterikatan emosional karyawan yang positif dan komitmen karyawan (Truss, dkk, 2014). Menurut Robbin (Bridger, 2015) employee engagement merupakan sikap positif yang dimiliki karyawan terhadap organisasi tempat ia bekerja serta nilai-nilai yang dimiliki oleh organisasi tersebut, dalam konsep employee engagement terdapat hubungan dua arah antara karyawan dengan perusahaan. Dapat disimpulkan, employee engagement merupakan keterikatan emosional karyawan yang positif dan komitmen karyawan terhadap organisasi tempat ia bekerja serta nilai-nilai yang dimiliki oleh organisasi tersebut.

Faktor yang dapat memicu terciptanya employee engagement menurut McBain (2007) salah satunya yaitu, working life yang merupakan kondisi lingkungan kerja yang nyaman atau iklim organisasi yang dipersepsikan baik oleh karyawan. Sedangkan menurut Luthans (2005), salah satu faktor yang dapat meningkatkan employee engagement berhubungan dengan kondisi psikologis, yaitu safety yang dapat menimbulkan rasa percaya diri karyawan dalam bekerja.

Salah satu faktor individu yang mempengaruhi kinerja dalah efikasi diri. Efikasi diri menurut Bandura (1997) adalah keyakinan individu tentang kemampuan mereka sendiri untuk berhasil melakukan tugasnya dalam rangka untuk mendapatkan hasil yang diinginkan. Menurut Stajkovic dan Luthans (Luthans, 2005), efikasi diri mengacu pada keyakinan individu (konvidensi) mengenai kemampuannya untuk memobilisasi motivasi, sumber daya kognitif dan tindakan yang diperlukan agar berhasil melaksanakan tugas dalam konteks tertentu. Greenberg dan Baron (2003) menjelaskan, terdapat dua jenis efikasi diri yaitu efikasi diri khusus atau specific self-efficacy (SSE) dan efikasi diri umum atau general self-efficacy (GSE). SSE dan GSE sama-sama menunjukkan keyakinan terhadap kemampuan individu untuk 
mencapai hasil yang diinginkan, hanya saja SSE merujuk pada tugas tertentu dan spesifik sedangkan GSE menunjuk pada tugas-tugas yang bersifat umum, namun pada penelitian ini fokus pada GSE. Menurut Greenberg dan Baron (2003), efikasi diri memiliki tiga aspek yaitu magnitude, strength, generally.

Faktor lain yang mempengaruhi kinerja adalah persepsi karyawan terhadap iklim organisasi. Iklim organisasi adalah persepsi bersama secara formal dan informal terhadap kebijakan organisasi, kebiasaan dan prosedur yang berlaku di organisasi (Holloway, 2012). Steers dan Black (1994) berpendapat, iklim organisasi dapat dianggap sebagai kepribadian organisasi yang dilihat dan dirasakan oleh para anggotanya. iklim organisasi merupakan pemahaman karyawan terhadap kebijakan organisasi, kebiasaan dan prosedur yang berlaku di organisasi yang dapat mempengaruhi perilaku karyawan dalam mencapai tujuan organisasi.

Salah satu organisasi yang memiliki perhatian terhadap kinerja karyawan adalag BMT BIF. Baitul Maal wat Tamwil (BMT) merupakan lembaga keungan syari'ah yang menitik beratkan pada pemberdayaan ekonomi kelas bawah, seperti permodalan terhadap Usaha Mikro dan Kecil (UMK) dengan pola bagi hasil. Salah satu BMT yang menjadi pionir BMT-BMT di Indonesia terutama di Yogyakarta yaitu BMT BIF (Bina Ihsanul Fikri). BIF bukan merupakan BMT yang pertama kali berdiri di Yogyakarta, namun BIF menunjukkan prestasi kerja yang sangat baik. Setiap tahun, pertumbuhan anggota atau nasabah, keuangan dan perkembangan lainnya selalu mengalami peningkatan. Hingga saat ini BIF memiliki 12 cabang yang berada di Yogyakarta, jumlah cabang yang dimiliki BIF termasuk dalam kategori yang banyak bila dibandingkan dengan BMT lainnya.

Persaingan bisnis dalam merebut pelanggan selalu saja terjadi yang pada akhirnya berdampak pada income perusahaan. Dalam menjalankan bisnisnya, BIF berkompetisi dengan rentenir dan lembaga keuangan mikro lainnya dalam merebut pasar, dan saat ini BIF juga berkompetisi dengan Bank-bank konvensional karena saat ini Bank konvensional mulai menyentuh usaha mikro. Banyak upaya yang dilakukan BIF untuk memperkuat bisnisnya, hal ini perlu didukung oleh kinerja karyawan BIF secara keseluruhan. Sesuai dengan hasil penelitian Kreitner dan Angelo (2001), kinerja yang efektif dapat menunjang implementasi strategis bisnis.

Banyak faktor yang dapat mempengaruhi kinerja organisasi, pada umumnya kinerja organisasi dipengaruhi oleh faktor internal dan eksternal karyawan. Faktor internal karyawan yang ingin dilihat dalam penelitian ini yaitu efikasi diri. Karyawan BIF diharapkan memiliki efikasi diri yang tinggi, karena dapat mempengaruhi motivasi dan kinerja mereka, hambatan dalam pekerjaan akan menjadi tantangan yang perlu dihadapi dan diselesaikan. Menurut Robbins (2008), semakin tinggi efikasi diri seseorang semakin besar pula kepercayaan dari orang tersebut terhadap kesanggupannya untuk berhasil dalam mengerjakan tugasnya.

Hasil penelitian Sholikhan dan Churiyah (2006) menyatakan bahwa iklim organisasi berpengaruh signifikan terhadap prestasi kerja karyawan baik langsung maupun tidak langsung. Iklim organisasi merupakan faktor eksternal yang mempengaruhi kinerja karyawan. Iklim organisasi yang dipersepsikan baik oleh karyawan dapat berpengaruh terhadap work engagement secara positif (Hakanen, Bakker dan Schaufeli, 2006). Engagement merupakan karakteristik karyawan yang memiliki komitmen terhadap organisasi, 
oleh karena itu karyawan yang engaged memiliki dedikasi kuat terhadap perusahaan sehingga akan bekerja lebih produktif dalam memajukan perusahaan.

Latar belakang permasalahan tersebut menjadi daya tarik peneliti untuk melihat faktor apa yang paling mempengaruhi kinerja karyawan BMT BIF ditinjau dari faktor internal karyawan yaitu efikasi diri dan faktor eksternal karyawan yaitu persepsi iklim organisasi dengan employee engagement sebagai variabel mediator.

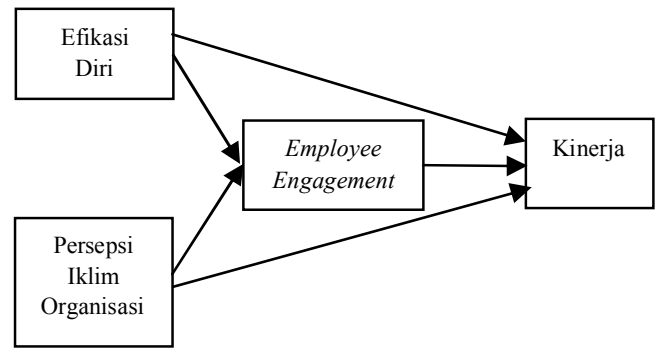

Gambar 1. Dinamika Konseptual

Penelitian Pengaruh Efikasi Diri dan

Persepsi Iklim Organisasi terhadap Kinerja dengan Employee Engagement sebagai Mediator

\section{Metode Penelitian}

Subjek pada penelitian ini adalah karyawan BMR BIF cabang Yogyakarta yang berjumlah 93 orang. Data dikumpulan dengan menggunakan skala. Skala kinerja yang disusun oleh peneliti berdasarkan aspek Bernardin (2003), yaitu; kualitas, kuantitas, ketepatan waktu, efektivitas pengeluaran, kebutuhan untuk diarahkan dan dampak interpersonal. Skala kinerja terdiri dari 18 item dengan lima pilihan jawaban berikut; sangat sering (SS), sering $(\mathrm{S})$, kadang-kadang $(\mathrm{K})$, jarang $(\mathrm{J})$ dan tidak pernah (TP). Employee engagement diukur menggunakan Gallup question 12 survey (Q12 survey) yang dikembangkan oleh organisasi Gallup dengan reliabilitas sebesar 0, 91 (Harter, dkk, 2006). Q12 survey dirancang berdasarkan 4 aspek, yaitu; how can We grow, do I belong, what do I give, what do I get (Gallup, 2013). Setelah diadaptasi, skala employee engagement berjumlah 12 item dengan lima kategori pilihan jawaban yaitu sangat sesuai (SS), sesuai (S), agak sesuai (AS), tidak sesuai (TS) dan sangat tidak sesuai (STS).

Efikasi diri diukur menggunakan new general self-efficacy scale (NGSE) yang terdiri dari 8 item dengan reliabilitas 0,92 dan 0.94 pada kelompok penelitian satu dan dua, namun tidak ada perbedaan yang signifikan antara reliabilitas kedua kelompok tersebut (Chen, Gully, \& Eden, 2001). Skala ini dirancang berdasarkan tiga aspek yang dikemukakan oleh Greenberg dan Baron (2003) yaitu, magnitude, strength, generally. Setelah diadaptasi, skala efikasi diri berjumlah 9 item dengan lima kategori pilihan jawaban yaitu sangat sesuai (SS), sesuai (S), agak sesuai (AS), tidak sesuai (TS) dan sangat tidak sesuai (STS). Persepsi karyawan terhadap iklim organisasi diukur menggunakan new organizational climate scale yang dirancang oleh Peña-Suárez, dkk yang terdiri dari 15 item, skala ini telah diujikan pada 3.163 pekerja Dinas Kesehatan di Kerajaan Asturias, Spanyol dengan reliabilitas sebesar 0,94. New organizational climate scale dirancang berdasarkan 8 aspek yang dikemukakan oleh Koys dan Docotiis (Burton dan Obel, 2004), yaitu; otonomi, kohesifitas, kepercayaan, tekanan, dukungan, pengakuan, keadilan, inovasi. Setelah diadaptasi, skala persepsi terhadap iklim organisasi berjumlah 16 item dengan lima kategori pilihan jawaban yaitu sangat sesuai (SS), sesuai (S), agak sesuai (AS), tidak sesuai (TS) dan sangat tidak sesuai (STS).

Teknik analisis data menggunakan metode structural equation modeling 
(SEM) yang dioperasikan dengan program AMOS. Metode structural jalur secara teoritis dikembangkan berdasarkan variabel-variabel bebas yang berpengaruh nyata terhadap variabel terikat. SEM merupakan metode statistik yang digunakan untuk menguji hipotesis yang terstruktur (Sugiyono, 2014).

\section{Hasil dan Pembahasan}

Hasil uji normalitas data secara univariate dilakukan dengan mengamati nilai skewness data, apabila nilai CR skew dan CR kurtosis berada diantara rentang \pm 2,58 dengan tingkat signifikansi 0,05, maka data penelitian yang digunakan dikatakan normal. Pada tahap ini, item kinerja nomor 4 dan item efikasi diri no 6 gugur karena datanya tidak normal.

Uji normalitas data secara multivariate menunjukkan nilai sebesar 3,660, yakni $>2,58$ yang berarti secara multivariate data tidak normal, sehingga perlu dilakukan bootsrap, yaitu suatu prosedur yang dilakukan dengan resampling dimana sampel asli diperlakukan sebagai populasi. Bollen-Stine Bootstrap dengan sampel 500 menghasilkan nilai rata-rata chi-square sebesar 220,768 dan nilai probabilitas 0,140 yakni $>0,05$ (tidak signifikan), hal ini berarti bahwa model dapat diterima.

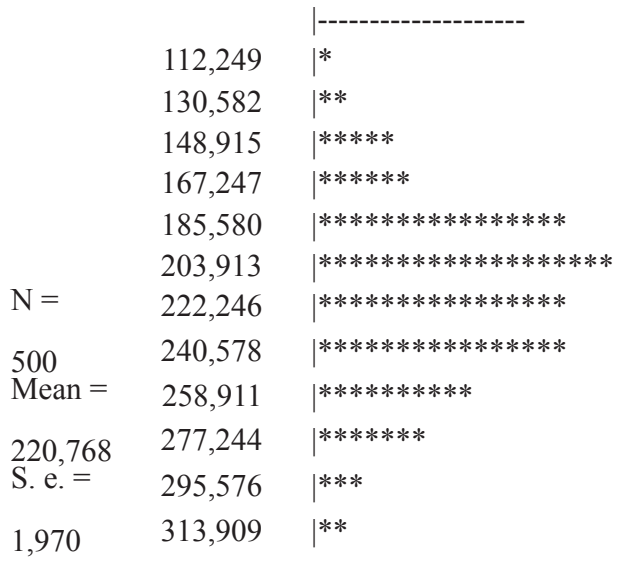

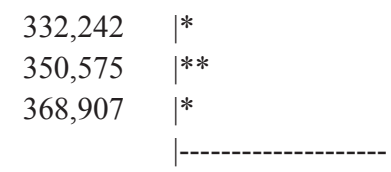

Gambar 2. Histogram Bolle-Stine Bootstrap

Grafik tersebut menunjukkan nilai kluster di pusat dengan multivariate normal dan distribusi chi-square termasuk normal karena terdapat beberapa nilai di atas dan di bawah 220,768 yang sebanding.

Uji kesesuaian model dilakukan dalam tiga tahapan hingga model fit. Tahap pertama menguji semua item dan hasilnya menunjukkan data belum fit. Agar model fit, maka item yang memiliki factor loading $<0,50$ digugurkan, item K14, K15, EE12, IO16 digugurkan dan dilakukan pengujian lagi.

Tahap ke dua menguji item-item yang memiliki loading factor $>0,50$, namun hasilnya data belum fit. Sehingga dilakukan pengguguran dengan melihat nilai normalitas data yakni berada diantara rentang $\pm 2,58$, item ED6 dan K4 gugur pada tahap ini, namun hasilnya belum fit.

Tahap ke tiga pengujian dilakukan pengguguran item dengan melihat standardized residual covariances, yaitu menggugurkan salah satu item yang memiliki nilai residual di atas $\pm 2,58$. Langkah ini digunakan sesuai dengan penjelasan Ghozali (2014) bahwa dua jenis informasi yang dapat digunakan untuk mendeteksi adanya kesalahan spesifikasi model yaitu nilai standardized residual dan modification index.

Hasil akhir proses pemilihan item berdasarkan standardized residual menghasilkan 3 item untuk variabel efikasi diri, 8 item untuk variabel persepsi iklim organisasi, 4 item untuk variabel employee engagement dan 6 item untuk variabel kinerja. Masing-masing aspek terwakili oleh 
satu item yang dapat dilihat pada gambar berikut ini.

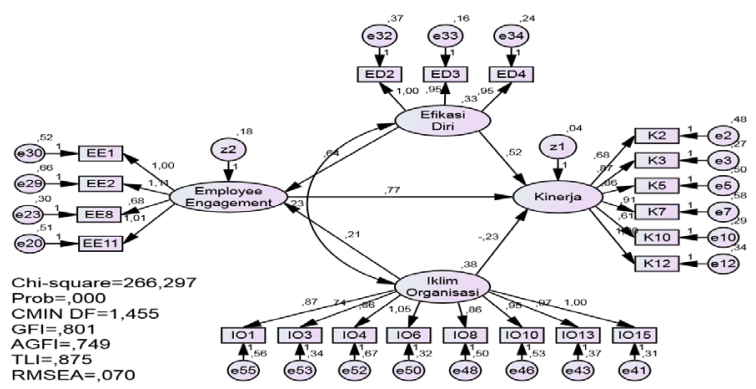

Gambar 2. Uji Kesesuaian Model Tahap Ke Tiga

Hasil uji menunjukkan nilai chisquare 266,297 dan probabilitas 0,000, yang berarti signifikan atau belum fit. Menurut Ghozali (2014) chi-square sangat sensitif terhadap jumlah sampel sehingga terdapat kecenderungan nilai chi-square akan selalu signifikan, jika nilai chi-square signifikan maka dianjurkan untuk mengabaikan dan melihat ukuran goodness fit lainnya. Berikut ini merupakan hasil pengujian goodness of fit berdasarkan kriteria yang dikemukakan Yamin dan Kurniawan (2009).

Tabel 1. Hasil Pengujian Goodness of Fit

\begin{tabular}{lccc}
\hline $\begin{array}{c}\text { Goodness of } \\
\text { Fit Index }\end{array}$ & Kriteria & $\begin{array}{c}\text { Cut of } \\
\text { Value }\end{array}$ & Ket. \\
\hline Chi-square & Harus kecil & 266,297 & Tidak fit \\
Significant & $\geq 0,05$ & 0,000 & Tidak fit \\
Probability & & & \\
RMSEA & $\leq 0,08$ & 0,070 & Good fit \\
CMIN/DF & $\leq 2,00$ & 1,455 & Fit \\
GFI & $0-1$ & 0,801 & Fit \\
AGFI & $0,8 \leq \mathrm{AGFI} \geq 0,9$ & 0,749 & Tidak fit \\
TLI & $0,8 \leq \mathrm{TLI} \geq 0,9$ & 0,875 & Marginal fit \\
CFI & $0,8 \leq \mathrm{CFI} \geq 0,9$ & 0,891 & Marginal fit \\
IFI & $0,8 \leq \mathrm{IFI} \geq 0,9$ & 0,895 & Marginal fit \\
\hline
\end{tabular}

Uji signifikansi peran langsung variabel penelitian dilakukan dengan menganalisis nilai Critical Ratio (CR) dan nilai Probability (P). Hasil yang diperoleh dibandingkan dengan batasan statistik yang disyaratkan, untuk nila $\mathrm{CR}>1,96$, sedangkan nilai $\mathrm{P}$ menggunakan signifikansi 0,05 . Apabila nilai dari hasil olah data memenuhi syarat tersebut, maka hipotesis penelitian yang diajukan dapat diterima.

Tabel 2. Peran Langsung Variabel Penelitian

\begin{tabular}{|c|c|c|c|c|c|c|c|}
\hline Variabel & $\begin{array}{l}\text { Pengaruh } \\
\text { Langsung }\end{array}$ & Variabel & CR & $\mathbf{P}$ & B & r2 & Ket. \\
\hline $\begin{array}{l}\text { Employee } \\
\text { engagement }\end{array}$ & & Efikasi diri & 3,083 & 0,002 & 0,587 & 0,345 & Sig. \\
\hline $\begin{array}{l}\text { Employee } \\
\text { engagement }\end{array}$ & & $\begin{array}{l}\text { Persepsi } \\
\text { iklim } \\
\text { organisasi }\end{array}$ & 1,267 & 0,205 & 0,208 & 0,043 & $\begin{array}{c}\text { Tidak } \\
\text { sig. }\end{array}$ \\
\hline Kinerja & & $\begin{array}{l}\text { Persepsi } \\
\text { iklim } \\
\text { organisasi }\end{array}$ & $-1,587$ & 0,112 & $-0,206$ & 0,042 & $\begin{array}{c}\text { Tidak } \\
\text { sig. }\end{array}$ \\
\hline Kinerja & & $\begin{array}{l}\text { Employee } \\
\text { engagement }\end{array}$ & 3,418 & 0,000 & 0,715 & 0,511 & Sig. \\
\hline Kinerja & & Efikasi diri & 2,217 & 0,027 & 0,440 & 0,194 & Sig. \\
\hline
\end{tabular}

Efikasi diri memiliki peranan langsung terhadap employee engagement dengan koefisien parameter sebesar 0,587 dan nilai $P$ lebih kecil dari 0,05. Sumbangan efektif efikasi diri terhadap employee engagement sebesar 34,5\%. Hasil tersebut menunjukkan bahwa efikasi diri dapat mempengaruhi ketirakatan karyawan terhadap perusahaan. Persepsi iklim organisasi tidak memiliki peranan langsung terhadap employee engagement dengan koefisien parameter sebesar 0,208 dan nilai P lebih besar dari 0,05 . Sumbangan efektif persepsi iklim organisasi terhadap employee engagement hanya sebesar $4,3 \%$.

Persepsi iklim organisasi tidak berperan dalam meningkatkan kinerja karyawan dengan koefisien parameter sebesar -0,206 dan nilai P lebih besar dari 0,05 . Sumbangan efektif persepsi iklim organisasi terhadap kinerja hanya sebesar 4,2\%. Hasil ini menolak hipotesis 3 yang menyatakan terdapat peran persepsi iklim organisasi terhadap kinerja dengan bukti empirik yaitu koefisien parameter sebesar 
$-0,206$ dan nilai $\mathrm{P}>0,05$.

Employee engagement memiliki peranan langsung terhadap kinerja dengan koefisien parameter sebesar 0,715 dan nilai $P$ lebih kecil dari 0,05. Sumbangan efektif employee engagement terhadap kinerja sebesar 51,1\%. Hasil tersebut menunjukkan bahwa keterikatan karyawan terhadap perusahaan dapat mempengaruhi kinerja karyawan.

Efikasi diri memiliki peranan langsung terhadap kinerja dengan koefisien jalur sebesar 0,440 dan nilai $\mathrm{P}$ lebih kecil dari 0,05 . Sumbangan efektif efikasi diri terhadap kinerja sebesar 19,4\%. Hasil tersebut menerima hipotesis 1 yang menyatakan terdapat pengaruh efikasi diri terhadap kinerja, yang artinya semakin tinggi efikasi diri karyawan maka kinerjanya semakin baik.

Pengujian peran tidak langsung bertujuan untuk mendeteksi kedudukan variabel mediasi dalam suatu model. Pemeriksaan variabel mediasi dapat dilakukan dengan cara mengalikan nilai koefisien jalur pengaruh variabel bebas dengan variabel modiator dan nilai koefisien jalur pengaruh variabel modiator dengan variabel terikat. Metode lainnya yaitu menggunakan analisis Test Sobel Statistic dengan membandingkan nilai statistik Sobel dan P value kurang dari 0,05 yang berarti bahwa efek mediasi berlaku pada model yang diuji.

Penelitian ini memiliki dua pengujian tidak langsung, yaitu pengujian tidak langsung efikasi diri terhadap kinerja melalui employee engagement dan pengujian tidak langsung iklim organisasi terhadap kinerja melalui employee engagement. Hasil analisis data yang menjelaskan peran tidak langsung variabel dapat dilihat pada tabel berikut.
Tabel 3. Peran Tidak Langsung Variabel Penelitian

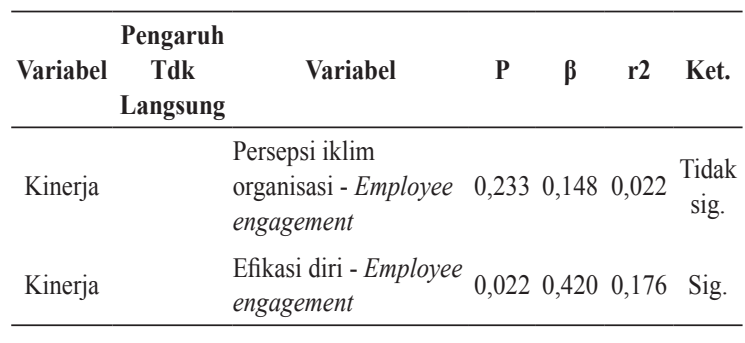

Employee engagement menjadi mediator dari persepsi iklim organisasi terhadap kinerja dengan koefisien parameter sebesar 0,148 dan $\mathrm{P}$ value di atas 0,05. Sumbangan efektif persepsi iklim organisasi terhadap kinerja yang dimediasi oleh employee engagement hanya sebesar 2,2\%. Hasil tersebut menunjukkan bahwa peran persepsi iklim organisasi terhadap kinerja yang dimediasi oleh employee engagement tidak signifikan, sehingga hipotesis 4 yang menyatakan terdapat peran persepsi iklim organisasi terhadap kinerja dengan employee engagement sebagai mediator ditolak. Employee engagement menjadi mediator peranan efikasi diri terhadap kinerja dengan koefisien parameter sebesar 0,420 dan P value dibawah 0,05. Sumbangan efektif efikasi diri terhadap kinerja yang dimediasi oleh employee engagement sebesar 17,6\%. Hasil tersebut menunjukkan bahwa employee engagement dapat menjadi mediasi efikasi diri terhadap kinerja. Bukti empirik tersebut dapat menerima hipotesis 2 yang menyatakan terdapat peran efikasi diri terhadap kinerja dengan employee engagement sebagai mediator.

Kinerja itu dipengaruhi oleh dua faktor yaitu faktor internal karyawan dan faktor eksternal karyawan. Faktor internal yaitu merupakan faktor yang berasal dari dalam diri individu yang bersangkutan, seperti efikasi diri, skill, IQ dan lainnya. Sedangkan faktor eksternal karyawan yaitu faktor yang berasal dari lingkungan 
kerja organisasinya, seperti iklim kerja yang dinamis, peluang karir, fasilitas yang memadai dan lainnya. Faktor internal dan eksternal tersebut merupakan jenisjenis atribusi yang mempengaruhi kinerja karyawan. Suatu organisasi atau perusahaan memiliki strategi yang berbeda-beda untuk meningkatkan kinerja karyawannya, ada yang menekankan pada faktor eksternal, faktor internal, maupun kombinasi keduanya.

BMT BIF sebagai lembaga keungan syariah yang menitik beratkan pada pemberdayan ekonomi kelas bawah dan berbasiskan dakwah, melakukan strategi peningkatan kinerja yang menekankan pada faktor internal. Hal ini dimulai sejak proses perekrutan dengan memilih karyawan yang memiliki sifat jujur, amanah dan pengamalan agamanya baik. Proses pembinaanpun menekankan pada pembentukan akhlak yang islami dan amanah, salah satu contoh aktivitasnya yaitu ngaji bersama selama satu jam yang dilakukan setiap Jum'at pagi. Metode yang diterapkan BMT BIF tersebut, diharapkan akan membentuk karyawan yang memiliki pribadi yang berakhlak islami dan memiliki etos kerja yang tinggi. Jika pribadi karyawan BMT BIF telah terbentuk dan stabil, maka faktor eksternal tidak berpengaruh terhadap kinerja.

Sesuai dengan temuan penelitian berikut ini, diketahui bahwa peran langsung efikasi diri terhadap kinerja dengan koefisien jalur sebesar 0,440 dan nilai $\mathrm{P}<0,05$. Hal ini menunjukkan sumbangan efektif terhadap kinerja sebesar 19,4\%. Semakin tinggi efikasi diri karyawan BIF maka kinerjanya semakin baik. Peran efikasi diri terhadap kinerja pada penelitian ini didukung oleh hasil penelitian Alessandri, Borgogni, dan Truxillo (2015) yang mengemukakan efikasi diri secara signifikan dapat memprediksi tingkat prestasi kerja individu. Serta penelitian Prasetya (2013), efikasi diri berhubungan dengan kepuasan kerja dimana jika seseorang memiliki efikasi diri yang tinggi maka cenderung untuk berhasil dalam tugasnya serta meningkatkan kepuasan atas apa yang dikerjakannya.

Hubungan efikasi diri terhadap kinerja diperkuat dengan teori Bandura yang menyatakan, kinerja individu memiliki relevansi tinggi terhadap organisasi dan individu yang bersangkutan. Kinerja tinggi muncul ketika individu puas terhadap hasil tugasnya, dipengaruhi peran efikasi diri dan penguasaan terhadap tugas (Sonnentang, Volmer, \& Spychala, 2010). Namun efikasi diri harus diikuti dengan pengetahuan, keahlian, keterampilan, sumber daya, serta peluang yang dimiliki oleh individu, karena tanpa hal tersebut maka tidak cukup untuk memotivasi individu dalam meningkatkan kinerjanya (Meyer, 2007).

Efikasi diri juga memiliki peranan langsung terhadap employee engagement dengan koefisien parameter sebesar 0,587 dan nilai $\mathrm{P}<0,05$. Sumbangan efektif efikasi diri terhadap employee engagement sebesar $34,5 \%$. Hasil ini menunjukkan bahwa efikasi diri dapat mendorong kemauan karyawan untuk terikat dengan perusahaan. Temuan ini didukung oleh hasil penelitian Luthans, dkk (2008) yang menyatakan bahwa efikasi diri memiliki hubungan yang signifikan terhadap employee engagement. Hasil penelitian Niu (2010) menyatakan karyawan yang memiliki efikasi diri tinggi berkomitmen terhadap pekerjaannya. Komitmen merupakan salah satu aspek dari employee engagement.

Employee engagement memiliki peranan langsung terhadap kinerja dengan koefisien parameter sebesar 0,715 dan nilai $\mathrm{P}<0,05$. Nilai ini menunjukkan bahwa sumbangan efektif employee engagement terhadap kinerja sebesar 51,1\%. Artinya, keterikatan karyawan terhadap perusahaan dapat mempengaruhi kinerja karyawan. 
Temuan tersebut diperkuat dengan hasil penelitian terdahulu yang memperlihatkan pengaruh signifikan antara employee engagement dan kinerja karyawan (Wellins, Bernthal \& Phelps, 2006). Kinerja pada level organisasi, level individu dan kelompok secara signifikan dipengaruhi oleh work engagement (Chaudhary, Rangnekar \& Barua, 2012).

Beberapa penelitian terdahulu menjelaskan dampak employee engagement pada individu. Employee engagement mempengaruhi kualitas kerja karyawan, meningkatkan kepuasan kerja, mengurangi jumlah ketidak hadiran karyawan dan menurunkan kecenderungan untuk berpindah pekerjaan. Hal ini disebabkan karena karyawan yang memiliki derajat engagement yang tinggi akan memiliki keterikatan emosi yang tinggi pada organisasi. Keterikatan emosi yang tinggi mempengaruhi karyawan dalam menyelesaikan pekerjaan (cenderung memiliki kualitas kerja yang memuaskan) dan akan berdampak pada rendahnya keinginan karyawan untuk meninggalkan pekerjaan atau perusahaan.

Employee engagement menjadi mediator peranan efikasi diri terhadap kinerja dengan koefisien parameter sebesar 0,420 dan $\mathrm{P}$ value $<0,05$. Hasil tersebut menunjukkan sumbangan efektif efikasi diri terhadap kinerja yang dimediasi oleh employee engagement sebesar 17,6\%. Efikasi diri merupakan kepercayaan diri karyawan terhadap kemampuannya untuk melakukan pekerjaan dengan baik dalam mencapai tujuan, apabila karyawan yakin terhadap kemampuannya, mau mencapai tujuan dan ingin mengembangkan karirnya, makan ia akan tinggal lama di perusahaan dan lebih produktif dalam bekerja. Hasil penelitian Miraglia, Alessandri \& Borgogni (2015), menyatakan bahwa efikasi diri memiliki peranan penting dalam mempertahankan tingkat kinerja yang tinggi dari waktu ke waktu.

Persepsi iklim organisasi tidak berperan dalam meningkatkan kinerja karyawan dengan koefisien parameter sebesar -0,206 dan nilai $\mathrm{P}$ lebih besar dari 0,05 . Hasil tersebut menunjukkan sumbangan efektif persepsi iklim organisasi terhadap kinerja hanya sebesar 4,2\%. Sedangkan peran persepsi iklim organisasi terhadap employee engagement memiliki koefisien parameter sebesar 0,208 dan nilai $\mathrm{P}>0,05$. Hasil penelitian ini menunjukkan bahwa persepsi iklim organisasi tidak berperan dalam menciptakan keterikatan karyawan terhadap perusahaan (employee engagement). Hasil tersebut diperkuat dengan pendapat McBain (2007) yang menyatakan faktor-faktor penggerak employee engagement akan berbeda di setiap jenis perusahaan. Oleh karena itu, tidak selamanya persepsi iklim organisasi mempengaruhi kinerja.

Penjelasan di atas menunjukkan peran persepsi iklim organisasi terhadap kinerja baik secara langsung atau dimediasi oleh employee engagement tidak signifikan, dilihat dari koefisien parameter persepsi iklim organisasi terhadap kinerja sebesar $-0,206$ dan nilai $\mathrm{P}>0,05$. Serta koefisien parameter peran persepsi iklim organisasi terhadap kinerja yang dimediasi oleh employee engagement sebesar 0,148 dan $\mathrm{P}$ value $>0,05$. Hubungan yang tidak signifikan ini diperkuat dengan hasil penelitian Wilderom, Glunk dan Maslowski (2000) yang meringkas 10 penelitian mengenai iklim organisasi dan kinerja, hasil tersebut menjelaskan bahwa setiap penelitian memiliki aspek iklim organisasi terpenting atau dominan yang berbeda. Hal ini dapat disebabkan oleh metode penelitian yang digunakan bervariasi serta subjek penelitian yang berbeda sehingga hasil penelitian yang 
didapatpun berbeda.

Seperti hasil penelitian ini yang dilaksanakan di BMT BIF, di ketahui bahwa persepsi iklim organisasi tidak berpengaruh terhadap kinerja karyawan baik secara langsung atau dimediasi oleh employee engagement. BMT BIF merupakan lembaga keuangan mikro yang bertujuan untuk membantu memberdayakan ekonomi masyarakat kelas bawah, dapat dikatakan bahwa BMT BIF bukan merupakan perusahaan profit murni melainkan ada unsur sosial di dalamnya. Sehingga loyalitas karyawan dalam bekerja memiliki peranan yang sangat besar dalam mencapai tujuan perusahaan, karyawan yang loyal akan berusaha memberikan hasil kerjanya yang terbaik. Oleh karena itu iklim organisasi di BMT BIF tidak berpengaruh terhadap kinerja karyawan.

\section{Simpulan}

Berdasarkan hasil penelitian yang didapat disimpulkan bahwa efikasi diri memiliki peranan yang besar dalam meningkatkan kinerja karyawan, baik peran secara langsung ataupun dimediasi oleh employee engagement. Persepsi iklim organisasi tidak mempengaruhi kinerja karyawan baik secara langsung ataupun dimediasi oleh employee engagement. Kinerja karyawan BMT BIF lebih dipengaruhi oleh faktor internal karyawan yaitu efikasi diri, efikasi diri memiliki peranan yang besar dalam mewujudkan engagement karyawan terhadap perusahaan sehingga karyawan bekerja dengan maksimal, sedangkan kebiasaan dan prosedur yang berlaku di perusahaan yang merupakan faktor eksternal tidak mempengeruhi kinerja karyawan. Kinerja karyawan BIF yang tinggi disebabkan oleh faktor individunya bukan karena faktor organisasinya

\section{Daftar Pustaka}

Alessandri, G., Borgogni, L., \& Truxillo, D. M. (2015). Tracking Job Performance Trajectories Over Time: A SixYear Longitudinal Study. European Journal of Work and Organizational Psychology, 25, 560-577.

Aon Hewitt. (2015). 2015 Trends in Global Employee Engagement: Making Engagement Happen.

Bandura, A. (1997). Self Efficacy: The Exercise of Control. New York: W. H. Freeman and Company.

Bakker, A. B., \& Bal, M. (2010). Weekly work engagement and performance: A study among starting teachers. Journal of Occupational and Organizational Psychology, 83, 189-206.

Bakker, dkk. (2007). Job resources boost work engagement, particularly when job demands are high. Journal of Educational Psychology, 99, 274-284.

Baron, A. R., \& Jerald, G. (2000). Behavior in Organization: Understanding and Managing The Human Side of Work. Canada: Prentice Hall International Inc.

Bernardin, H. J. (2003). Human resource management: An experiential approach. New york: McGraw-Hill, Inc.

BMTBIF (2013). Profile Lembaga Keuangan Syari'ah BMT 'Bina Ihsanul Fikri' 2014. Yogyakarta.

Bonner, S. E., \& Sprinkle, G. B. (2002). The Effect of Monetary Incentive on Effort and Task Performance: Theories, Evidence and Framework of Research. Accounting, Organization 
and Society, 27, 303-345.

Borman, dkk. (2003). HandBook of Psychology: Volume 12 Industrial and Organizational Psychology. Canada: John Wiler \& Sons, Inc.

Bridger, E. (2015). Employee Engagement. United States: Kogan Page.

Burton, R. M., \& Obel, B. (2004). Strategic Organizational Diagnosis and Design: The Dynamic of Fit (3rd ed.). New York: Springer Science+Business Media.

Chen, G., Gully, S. M., \& Eden, D. (2001). Validation of a New General SelfEfficacy Scale. Organizational Research Methods, 4, 62-83.

Chaudhary, R., Rangnekar, S., \& Barua, M. K. (2012). Relationships between occupational self efficacy, human resource development climate, and work engagement. Team Performance Management, 18, 370-383.

Chaudhary, R., Rangnekar, S., \& Barua, M. (2010). Relation Between Human Resource Development Climate and Employee Engagement: Result from India. Europe's Journal of Psychology, 7, 664-685.

Dessler, G. (2000). Human Resources Management. New Jersey: Prentice Hall Inc.

Fleming, J. H., \& Asplund, J. (2007). Where Employee Engagement Happens. Business Joournal.

HYPERLINK “http://www.gallup.com/ businessjournal/102496/whereemployee-engagement-happens. aspx" http://www.gallup.com/ businessjournal/102496/where- employee-engagement-happens.aspx

Gallup (2013). Statee of Global Workplace: Employee Engagement Insights for Business Leader Worldwide.

Greenberg, J., \& Baron, R. A. (2003). Behavior in Organization: Understanding ang Managing the Human side of Work (8th ed.). USA: Prentice-Hall, Inc.

Gibson, dkk. (2012). Organizations: Behavior, Structure, Process (14th ed.). New York: McGraw-Hill.

Ghozali, I. (2011). Konsep dan aplikasi dengan program AMOS 22.0. Semarang: Badan Penerbit Universitas Diponegoro.

Harter, dkk. (2006). Q12 Meta-Analysis. Washington DC: Gallup, Inc.

Hakanen, J. J., Bakker, A. B., \& Schaufeli, W. B. (2006). Burnout and Work Engagement Among Teachers. Journal of school psychology, 43, 495-513. BIBLIOGRAPHY $\backslash 1057$

Holloway, J. B. (2012). Leadership Behavior and Organizational Climate: An Empirical Study in a Non-profit Organizational. Emerging Leadership Journeys, 5, 9-35.

Jex, S. M., \& Britt, T. W. (2008). Organizational Pstchology: A Scientist-Practitioner Approach. USA: John Willey \& Sons, Inc.

Kreitner, R., \& Kinicki, A. (2005). Perilaku organisasi (Buku 1) (5th ed.). (E. Suandy, Penerj.) Jakarta: Salemba Empat.

Kusnendi.(2008). Model-Model Persamaan Struktural Satu dan Multigroup Sampel dengan LISREL. Bandung: 
Alfabeta.

Lussier, R. N. (2008). Human Relations in Organizations, Applications and Skill Building (7th ed.). New York: McGraw-Hill, Inc.

Luthans, F. (2005). Organizational Behavior (10th ed.). New York: McGraw-Hill Irwin.

Luthans, dkk. (2008). Impact of behavioral performance management in a Korean application. Leadership \& Organization Development Journal, 29, 427-443.

Lockwood, N. R. (2007). Leveraging Employee Engagement for Competitive Advantage. SHRM Research.

Matthews, dkk. (2000). Human Performance: Cognition, Stress and Individual Differences. Psychology Press: USA.

Meyer, L. H. (2007). Self-efficacy, Selfreliance, and Motivation in an Asynchronous Learning Environment. World Academy of Science, Engineering and Technology, 8, 717721.

Miraglia, M., Alessandri, G., \& Borgogni, L. (2015). Trajectory Classes of Job Performance; The Role of SelfEfficacy and Organizational Tenure. Career Development International, 20, 424-442.

McBain, R. (2007). The Practice of Engagement: Research into Current Employee Engagement Practice. Strategic HR Review, 6, 16-19.

Niu, H. (2010). Erratum to \& ldquo; Investigating the effects of self- efficacy on foodservice industry employees \& rsquo; career commitment. International Journal of hospitality Management, 29, 1336.

Prasetya, V., dkk. (2013). Peran Kepuasan Kerja, Self Esteem, Self Efficacy Terhadap Kinerja Individual. Jurnal Riset Manajemen dan Akuntansi, 1, 59-69.

Riggle, R. J. (2007). The impact of organizational climate variables of perceived organizational support, workplace isolation, and ethical climate on salesperson psychological and behavioral work outcomes. University of South Florida.

Robbins, S. P. (2008). Perilaku Organisasi (Edisi 12). Jakarta: Salemba Empat.

Salkind, N. (2006). Exploring Research. New Jersey: Prentice Hall.

Schermerhorn, J. R., dkk. (2012). Organizational Behavior. Hoboken: John Wiley \& Sons, Inc.

Shimazu, A., Schaufeli, W. B., Kamiyama, K., \& Kawakami, N. (2014). Workaholism vs. Work Engagement: the Two Different Predictiors of Future Well-being and Performance. International Journal of Behavioral Medicine, 22, 18-23.

Sholikhan., \& Churiyah, M. (2006). Analisis Jalur Iklim Organisasi Terhadap Komitmen dan Kepuasan Kerja Serta Implikasinya pada Prestasi Kerja. Jurnal Ekonomi Modernisasi, 2.

Steers, R. M,. \& Black, J. S. (1994). Organizational Behavior. New Jersey: Prentice Hall.

Sonnentang, S., Volmer, J., \& Spychala, 
A. (2010). Job Performance. Sage Handbook of Organizational Behavior, 1, 427-447.

Sugiyono. (2011). Metode Penelitian Kombinasi (Mixed Methods). Bandung: Alfabeta.

Timpe, A. D. (1992). The Art and Science of Business Management Performance, Mumbai: Jaico Publishing House.

Truss, C., dkk. (2014). Employee Engagement in Theory and Practice. New York: Routledge.

Vijay, M. V., \& Indradevi, R. (2015). A Study on Job Enrichment and Individual Performance among Faculties with Special Reference to Private
University. Mediterranean Journal of Social Sciences, 6, 252-260.

Wellins, R. S., Bernthal, P., \& Phelps, M. (2006). Employee Engagement: The Key to Realizing Competitive Adnvantage. America: Development Dimension International, Inc.

Wilderom, C. P. M., Glunk, U., \& Maslowski, R. (2000). Organizational Culture as a Predictor of Organizational Performance: Handbook of Organizational Culture and Climate.

Yamin, S., \& Kurniawan, H. (2009). Strucutral Equation Modeling: Belajar Lebih Mudah Teknik Analisis Data Kuistioner dengan Lisrel - PLS. Jakarta: Salemba Infotek. 